\title{
DETERMINATION OF FDM PRINTER SETTINGS WITH REGARD TO GEOMETRICAL ACCURACY
}

\author{
Roman Polak, Frantisek Sedlacek, Karel Raz
}
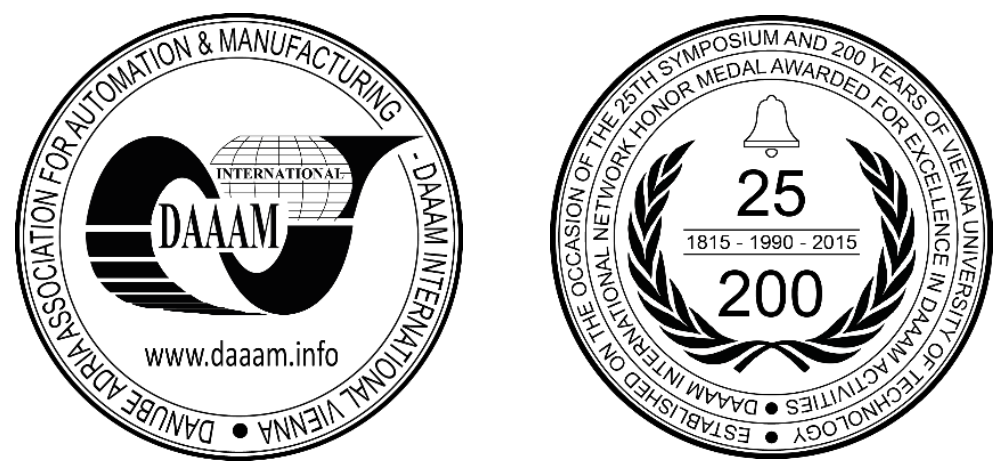

This Publication has to be referred as: Polak, R[oman]; Sedlacek, F[rantisek] \& Raz, K[arel] (2017). Determination of FDM Printer Settings with Regard to Geometrical Accuracy, Proceedings of the 28th DAAAM International Symposium, pp.0561-0566, B. Katalinic (Ed.), Published by DAAAM International, ISBN 978-3-902734-11-2, ISSN 1726-9679, Vienna, Austria

DOI: $10.2507 / 28$ th.daaam.proceedings.079

\begin{abstract}
Material extrusion is one of the most used additive technologies. The most common application of this technology is in the production of prototypes, preparations and small serial parts. This article deals with relationship between different model geometries and parameters such as temperature, speed of printing and height of layer. Typical features of this technology are ease of printing, but it depends on the type of material used and the particular device. Printers with Fused Deposition Modelling (FDM) technology have no feedback about printed material, such as printing accuracy. This paper aims to easily find ideal parameters for FDM printing technology using Polylactic Acid (PLA) material.
\end{abstract}

Keywords: Additive Manufacturing; FDM technology; Polylactic-Acid; 3D print parameters; Material extrusion

\section{Introduction}

Additive manufacturing technology, known as 3D print, is more widespread in some sectors. Producing parts via this method offers many advantages over traditional manufacturing technologies. The most frequently used type of technology is Fused Filament Fabrication (FFF) [1]. This term is equivalent to Fused Deposition Modeling (FDM) which is used as trademark by Stratasys Inc. Objects printed with this technology are layered and software (slicer) allows change many settings. Producers provide information about their printers such as minimum layer, accuracy, print bed size and other technical parameters [2]. But it may not apply to all printed parts with different geometries.

Most printers have recommended settings provided through the profile in slicers. Profiles depend only on used material, type of printer and does make a provision for type and properties of printed geometry. Many articles deal with dimensional accuracy in last phase of additive manufacturing. They solve printing inaccuracies with post processing [13][14]. The technology used for surface finalizing is vapor smoothing, but at the expense of dimensional accuracy [10][11]. This article is focused on dependency between model geometry and parameters such as temperature, speed of printing and height of layer. 


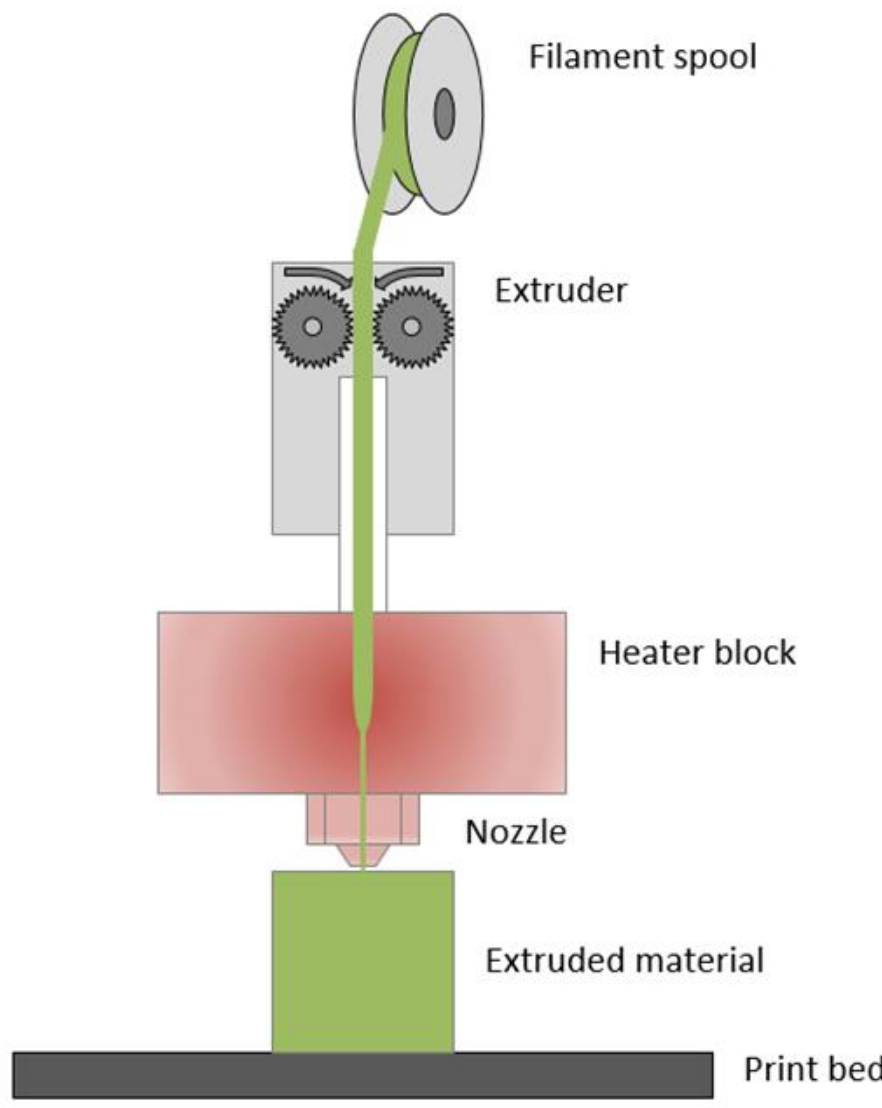

Fig. 1. FDM Technology

This technology is also known as "Material Extrusion". The material is loaded by an extruder (typically using a stepper motor) to the printer system [9]. Then is heated to a semi-liquid state by heater block and pressed through the nozzle to print bed. After the entire layer is applied, the pad is reduced by the thickness of the layer in the vertical axis and the gradual deposition continues again until the whole product is formed.

The abbreviations used below are trademarks of different manufacturers using the same technology [3]-[5]:

- FDM (Fused Deposition Modelling)

- PJP (Plastic Jet Printing)

- FFM (Fused Filament Modelling)

- MEM (Melted and Extruded Modelling)

- FFF (Fused Filament Fabrication)

- FLM (Fused Layer Modelling / Manufacturing)

\section{Material description}

The chosen material was Polylactic Acid (PLA). It is biodegradable material and is derived from renewable resources like corn starch or sugar cane. PLA with Acrylonitrile Butadiene Styrene (ABS) are the most used materials with material extrusion technology. PLA compared with ABS is easier and faster to print with the same initial conditions, but the products are significantly less resistant to higher temperatures. From the material point of view, PLA products are less flexible and glossier than ABS.

\begin{tabular}{|l|l|l|}
\hline Property & Value & Unit \\
\hline Melt Temperature & $173-178$ & ${ }^{\circ} \mathrm{C}$ \\
\hline Glass transition temperature & 60 & ${ }^{\circ} \mathrm{C}$ \\
\hline Heat Deflection Temperature at $455 \mathrm{kPa}$ & 65 & ${ }^{\circ} \mathrm{C}$ \\
\hline Density & 1.3 & $\mathrm{~g} / \mathrm{cm}^{3}$ \\
\hline Filament size & 1.75 & $\mathrm{~mm}$ \\
\hline Chemical formula & $\left(\mathrm{C}_{3} \mathrm{H}_{4} \mathrm{O}_{2}\right)_{\mathrm{n}}$ & \\
\hline
\end{tabular}

Table 1. Physical properties of the PLA 


\section{Testing procedure}

\subsection{Data preparation}

The FDM sample on following figure (Error! Reference source not found.) was used to verify the geometry with different settings of printer. This item was prepared in CAD software Siemens NX 11 [6]. In the drawing on figure (Fig. 2) are main parameters to verify with different printer settings. Source CAD data is [7].

Because software's for printers need stereo lithography file format (STL) [8], it was exported with following options. Chordal tolerance was set up to $0.05 \mathrm{~mm}$ and $5^{\circ}$ as angular tolerance, which is fully sufficient with regard to geometric shapes and print parameters. Smaller tolerance increase the detail of the export, but is unnecessary for printing with these specified parameters and only increases the size of the STL file.
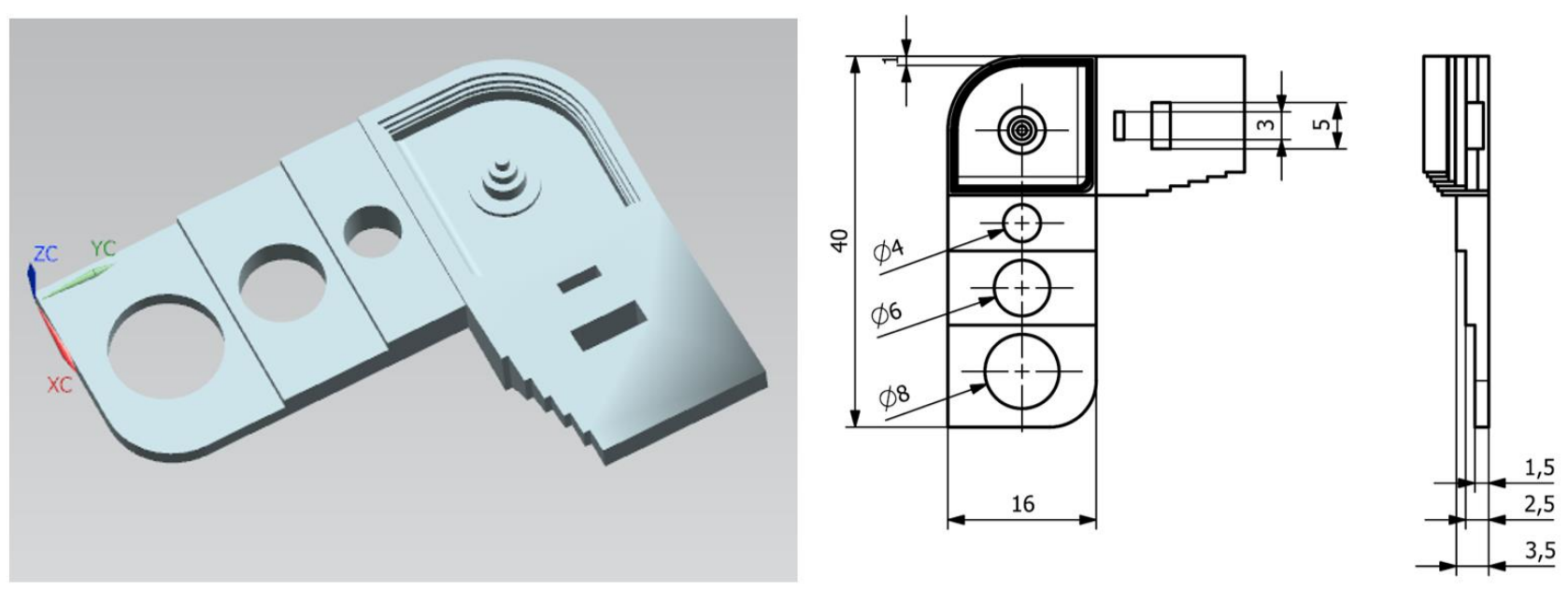

Fig. 2. CAD data with main drawing parameters

An STL file from Siemens NX was used as the input file for slicer software Cura 3.0.3. All printing parameters was set up in this slicer. Main parameters (speed, temperature and layer height) was changed in each print, but other parameters, such as printed line, cooling fan, bed heating, skirt etc. were the same for all printed samples. Printed line depends on nozzle diameter and must be the same as nozzle. Combination of bed heating and enabled cooling fan is the best for PLA bed adhesion with printing accuracy. Skirt ensures that the material is loaded into the entire printer device up to the print head.

All prints has the same settings. The main parameters are full infill, $0.5 \mathrm{~mm}$ size of nozzle, four walls, $40^{\circ} \mathrm{C}$ heated bed, print cooling from second layer etc. Tested parameters are temperature $\left(180^{\circ} \mathrm{C}, 200^{\circ} \mathrm{C}, 220^{\circ} \mathrm{C}\right)$, speed $(20 \mathrm{~mm} / \mathrm{s}$, $30 \mathrm{~mm} / \mathrm{s}, 40 \mathrm{~mm} / \mathrm{s})$ and layer height $(0.1 \mathrm{~mm}, 0.2 \mathrm{~mm})$ with all combinations. The printer working with G-code which is the output of this slicer software. The G-code is programming language with instructions for 3D printer. These instructions contain all the information's about print settings and model geometry converted to the print path.
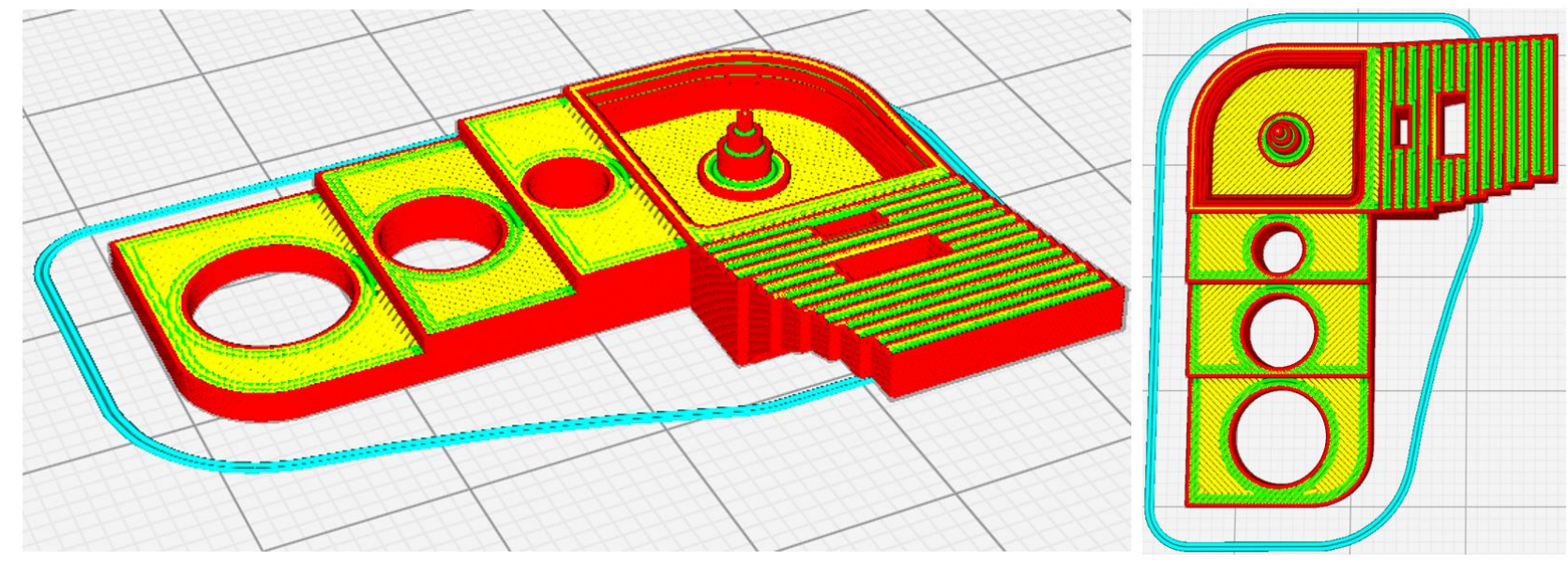

Fig. 3. Sample preparation in slicer Cura 


\subsection{Printing samples}

All samples were printed on FDM printer based on Prusa i3. The manufacturer provided axis accuracy $0.012 \mathrm{~mm}$ for $\mathrm{X}$ and $\mathrm{Y}$ and $0.0004 \mathrm{~mm}$ for $\mathrm{Z}$ axis. Heated bed can be heated up to $120^{\circ} \mathrm{C}$, but for PLA printing purposes is $60^{\circ} \mathrm{C}$ enough. Theoretical maximum printing speed is $150 \mathrm{~mm} / \mathrm{s}$ on printing area 200 x $280 \times 200 \mathrm{~mm}$.

Nozzle diameter is $0.4 \mathrm{~mm}$, but is customized by user from $0.2 \mathrm{~mm}$ to $0.5 \mathrm{~mm}$. The values bellow are parameters which was used for printing. A combinations of prints is compiled from these parameters and each of these prints has 3 copies to minimize errors.
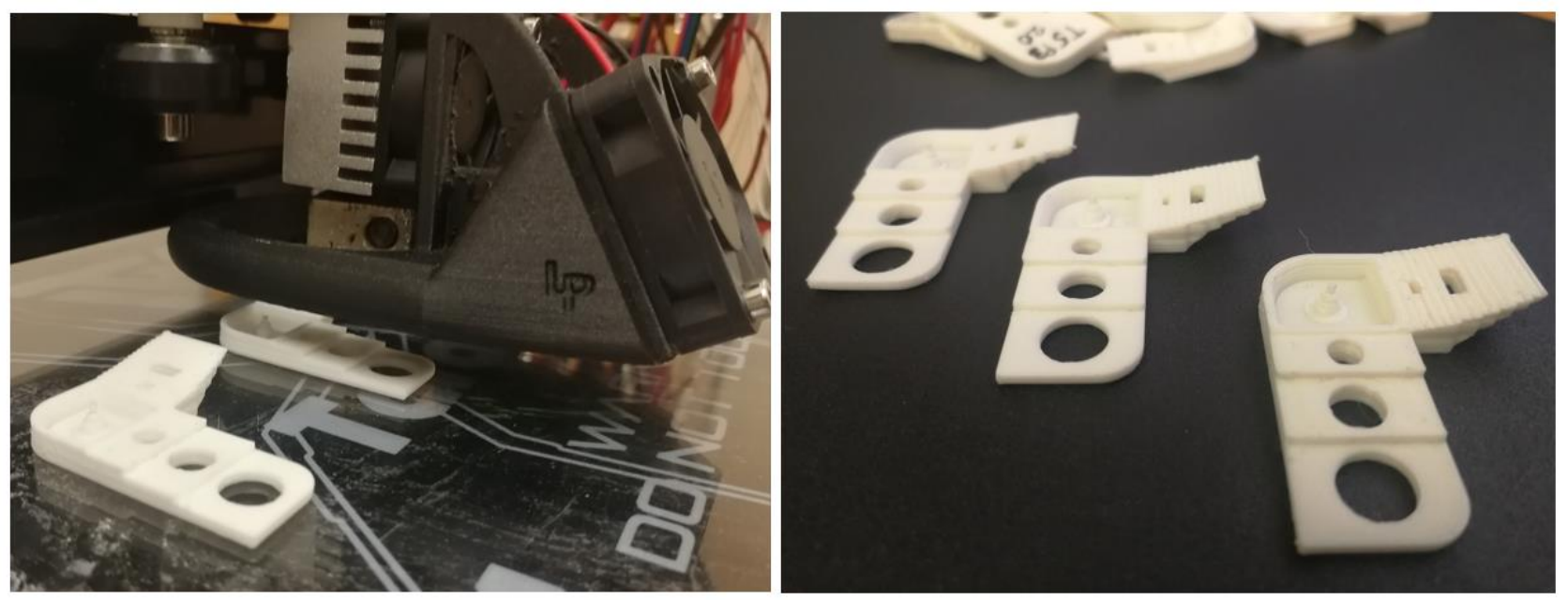

Fig. 4. Printed PLA samples

\subsection{Data analysis}

After the printing phase measurements and analysis are carried out. The FDM sample has many monitored and measure elements. All elements were measured and compared with the printer settings (speed, layer, temperature). There are elements circle 8 , circle 6 , circle 4 , rectangle 3 and rectangle 5 .

The shape (circle, rectangle) is the type of geometry and the numbers are diameters in millimetres. Than was monitored main values in all axis. The one diameter in $\mathrm{X}$ and $\mathrm{Y}$ axes. The $\mathrm{Z}$ diameter represent stair 1 , stair 2 and stair 3 . Where each stair has different height in the $\mathrm{Z}$ axis. The last parameter is minimum wall size. It means how accurate the thin wall is.

Data collected from all printed objects. Each print setting has 3 copies to minimize the errors rate. All prints have the same settings. The main parameters are full infill, $0.5 \mathrm{~mm}$ size of nozzle, four walls, $40^{\circ} \mathrm{C}$ heated bed, print cooling from second layer etc.

The tested parameters are temperature $\left(180^{\circ} \mathrm{C}, 200^{\circ} \mathrm{C}, 220^{\circ} \mathrm{C}\right)$, speed $(20 \mathrm{~mm} / \mathrm{s}, 30 \mathrm{~mm} / \mathrm{s}, 40 \mathrm{~mm} / \mathrm{s})$ and layer height $(0.1 \mathrm{~mm}, 0.2 \mathrm{~mm})$ with all combinations. Values in the chart above (Error! Reference source not found.) show percentage accuracy according to print tested parameters.

The parameter for Z-axis accuracy has similar balanced results (Stairs in schema). It cannot be said that any tested parameter affects the precision in the Z-axis. The samples with higher temperature show signs of greater fluidity and less accuracy. This problem is typically shown at minimum wall size parameter.

The circle geometries have bigger accuracy with bigger diameter. The same rule applies to the rectangular shape, bigger diameter has better accuracy. The best results of samples, it means with minimum deviation from the required dimensions, are a complex combination of the lower layer height $(0.1 \mathrm{~mm})$ and the lower temperature $\left(180^{\circ} \mathrm{C}\right)$. 


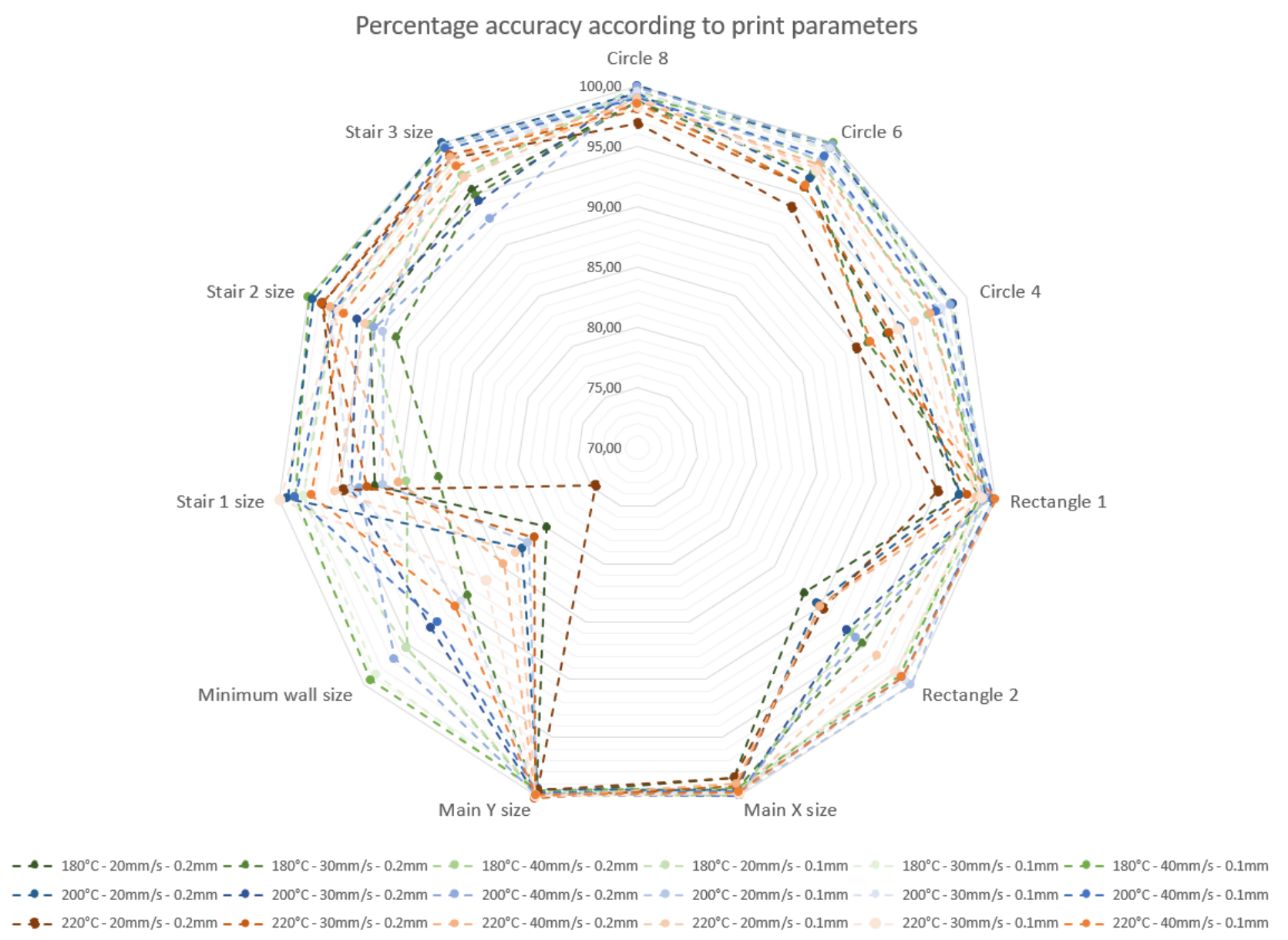

Fig. 5. Schema of data analysis

\section{Conclusion}

This paper describes the ideal settings of a Fused Deposition Modelling (FDM) printer. It is hard to find these settings during real production, therefore this experimental analysis was carried out. The collected data shows the dependence of the geometry on the print properties. The main tested parameters were speed, temperature and layer height. The results show the accuracy mainly depends on the temperature and layer height. The best results were obtained using lower temperature and thinner layer. Many articles deal with dimensional accuracy and model post processing with regard to the surface finish. The information contained in this article can be used for verification of these properties and finding the ideal parameters on other FDM devices.

This test has many possibilities for continuing and expanding the testing information for ideal FDM printer settings. Further research will continue with testing other print parameters, such as different nozzle sizes, other materials (ABS, Nylon, PETG etc.) and combining them with the parameters tested in this article.

\section{Acknowledgments}

This paper has been prepared under project LO1502 'Development of the Regional Technological Institute' under the auspices of the National Sustainability Programme I of the Ministry of Education of the Czech Republic aimed to the support research, experimental development and innovation.

\section{References}

[1] I. Gibson, D. Rosen, and B. Stucker. (2015). Introduction and Basic Principles in Additive Manufacturing Technologies, Springer New York, pp. 1-18, New York.

[2] C. Barnatt. 3D Printing: Third Edition. CreateSpace Independent Publishing Platform.

[3] ISO 17296:2015 - Additive manufacturing - General principles - Part 2: Overview of process categories and feedstock. ISO, 2015.

[4] ISO/ASTM 52915:2013 - Standard specification for additive manufacturing file format. International Organization for Standardization, Jun-2013. 
[5] ISO/ASTM 52900:2015 - Additive manufacturing - General principles - Terminology’. International Organization for Standardization, Dec-2015.

[6] D. I. Wimpenny, P. M. Pandey, and L. J. Kumar, Eds. (2017). Advances in 3D Printing \& Additive Manufacturing Technologies. Singapore: Springer Singapore, 2017.

[7] Siemens PLM. (2016) Siemens NX 11 User's Guide. Siemens AG..

[8] C. K. Chua and K. F. Leong. (2014) 3D Printing and Additive Manufacturing: Principles and Applications (with Companion Media Pack). Fourth Edition of Rapid Prototyping Fourth Edition. World Scientific Publishing Company.

[9] K. Kun. (2016). Reconstruction and Development of a 3D Printer Using FDM Technology. In Procedia Engineering, Volume 149, 2016, Pages 203-211, ISSN 1877-7058.

[10] Kozior T., Kundera C. (2017). Evaluation of the Influence of Parameters of FDM Technology on the Selected Mechanical Properties of Models. Procedia Engineering, Volume 192, 2017, Pages 463-468, ISSN 1877-7058.

[11] P.J. Nuñez, A. Rivas, E. García-Plaza, E. Beamud, A. Sanz-Lobera. (2015). Dimensional and Surface Texture Characterization in Fused Deposition Modelling (FDM) with ABS plus. Procedia Engineering, Volume 132, 2015, Pages 856-863, ISSN 1877-7058.

[12] Singh R., Singh J., Singh S. (2017). Investigation for surface finish improvement of FDM parts by vapor smoothing process. ISSN 1359-8368.

[13] Singh R., Singh J., Singh S. (2016). Investigation for dimensional accuracy of AMC prepared by FDM assisted investment casting using nylon-6 waste based reinforced filament. ISSN 0263-2241. 